\title{
FIRST DETECTION OF PASTEURELLA MULTOCIDA TYPE B:2 IN HUNGARY ASSOCIATED WITH SYSTEMIC PASTEURELLOSIS IN BACKYARD PIGS
}

\author{
Barbara UJVÁRI ${ }^{1}$, Levente SZEREDI ${ }^{2}$, László PERTL ${ }^{3}$, Gergely Tóth ${ }^{2}$, Károly ERDÉLYI $^{2}$, \\ Szilárd JÁNOSI ${ }^{2}$, Tamás MOLNÁR ${ }^{2}$ and Tibor MAGYAR ${ }^{1 *}$ \\ ${ }^{1}$ Institute for Veterinary Medical Research, Centre for Agricultural Research, Hungarian \\ Academy of Sciences, P.O. Box 18, H-1581 Budapest, Hungary; ${ }^{2}$ Veterinary Diagnostic \\ Directorate, Central Agriculture Office, Budapest, Hungary; ${ }^{3}$ Kisbér District Office, \\ Komárom-Esztergom County Government Office, Food Chain Safety and Veterinary \\ Directorate, Kisbér, Hungary
}

(Received 21 November 2014; accepted 17 February 2015)

This is the first report of Pasteurella multocida type B in Hungarian pigs. This disease was observed in backyard-raised pigs in three households within a small area. Neither the source of the infection nor the epidemiological connection between any of the premises could be determined. The most consistent lesion was dark red discolouration of the skin of the ventral neck and brisket, with accompanying oedema and haemorrhages. The morbidity was low and lethality relatively high, with three dead $(50 \%)$ and two euthanised $(33 \%)$ out of six affected animals. A total of three isolates of P. multocida (P55, P56 and P57) were cultured from these cases and examined in detail. These were identified as $P$. multocida ssp. multocida biovar 3. All were toxA negative and belonged to serotype B:2. Multilocus sequence typing was used to assign these to a new sequence type (ST61) that is closely related to other haemorrhagic septicaemia causing strains of $P$. multocida regardless of the host. M13 polymerase chain reaction and virulence-associated gene typing also show that type B strains form a highly homogeneous, distinct phylogenic group within $P$. multocida.

Key words: Pasteurella multocida, capsular type B, pig, generalised pasteurellosis, MLST

Pasteurella multocida is a widespread veterinary pathogen with zoonotic potential (Holst et al., 1992). As a primary pathogen, it is involved in the aetiology of fowl cholera (Rhoades and Rimler, 1989), atrophic rhinitis in pigs (Magyar and Lax, 2002), and haemorrhagic septicaemia (HS) in buffalo and cattle (De Alwis, 1992). As a secondary invader, it is associated with pneumonia in swine and ruminants as well as various respiratory tract diseases in rodents (Boyce et al., 2010).

*Corresponding author; E-mail: magyar.tibor@agrar.mta.hu; Phone: 0036 (1) 467-4092 
Based on the capsular structure and lipopolysaccharide composition, five capsular serogroups (A, B, D, E and F) and 16 somatic serotypes (1-16) have been identified (Carter, 1955; Heddleston et al., 1972; Rimler and Rhoades, 1987). These have been further divided into 14 biovars based on their ability to ferment sugar and enzyme activities (Fegan et al., 1995; Blackall et al., 1997). Finally, three subspecies have been identified by DNA-DNA hybridisation and carbohydrate fermentation patterns: ssp. multocida, ssp. septica and ssp. gallicida (Mutters et al., 1985). However, ssp. multocida and gallicida have been proven to belong to a single separate phylogenetic lineage, making their distinction questionable (Blackall et al., 1998; Christensen et al., 2004; Sellyei et al., 2011). Some serotypes of $P$. multocida are associated with host-specific diseases (Hotchkiss et al., 2011). Toxigenic type D and, more recently, type A strains have been connected with atrophic rhinitis in pigs. Non-toxigenic type A strains seem to be dominant in porcine and bovine respiratory diseases (Davies, 2004). Serotypes B:2 and E:2 are responsible for HS, an endemic disease of buffalo and cattle in Asia and Africa (Carter and De Alwis, 1989; De Alwis, 1992; Biswas et al., 2004).

Although acute septicaemic pasteurellosis is uncommon in pigs, sporadic outbreaks have been reported in limited geographical regions of the world (Gamage et al., 1995; Mackie, 1996; Townsend et al., 1998b; García et al., 2011). The patchy nature of these outbreaks suggests a relationship between HS-causing isolates of ruminants and swine. Using a repetitive, sequence-based polymerase chain reaction (REP-PCR) assay, P. multocida strains associated with porcine septicaemic pasteurellosis were found to be identical with HS-causing isolates from cattle (Townsend et al., 1997). Furthermore, the REP-PCR profiles were correlated with biovar 3 of HS isolates. The marked homogeneity of these strains suggests transmission between cattle and swine. Cardoso-Toset et al. (2013) reported an outbreak of septicaemic pasteurellosis in free-range pigs caused by a type B, biovar 13 P. multocida strain in Spain. Petersen et al. (2014) analysed MLST sequence data of 64 strains originating from cattle, buffalo and pigs, and identified sequence types (STs) typical of HS.

Here, we report the first detection of type B:2 P. multocida in Hungary, isolated from cases of generalised pasteurellosis in backyard pigs, with phenotypic and genotypic characterisation of the isolates. This report should inform practitioners and public health officials about a new threat to porcine health in Hungary.

\section{Materials and methods}

\section{Cases}

In August 2013, a new disease was detected among backyard pigs in three households within an area of $5 \mathrm{~km}$ diameter in north-western Hungary. These small operations had relatively few pigs, and only a small percentage of these 
were affected by the disease (Table 1). No epidemiological contacts were established between any of the affected households. The disease course varied from acute to chronic. The most characteristic clinical signs were swelling and purple discolouration of the ventral area of the neck, throat and abdomen, fever $\left(41-42{ }^{\circ} \mathrm{C}\right)$ and weakness. The discoloured areas were irregular, firm, painless and colder than adjacent normal skin. One animal had anorexia and weakness, and recovered without treatment in a few days (Farm B). One porker from Farm A was euthanised after unsuccessful antibiotic treatment with penicillin and streptomycin (Tardomyocel comp. III, Bayer AG, Leverkusen, Germany) at $0.06 \mathrm{~mL} / \mathrm{kg}$, and was submitted for necropsy (Case 1). Another porker from Farm B was euthanised after 3 weeks and submitted for necropsy (Case 2), as severe skin lesions persisted despite the same antibiotic treatment as used on Farm A. On Farm C, two piglets died suddenly without evident clinical signs. One of these animals (Case 4) and a sow (Case 3) that died after a half day of illness (consisting of tetraparesis, opisthotonus, fever and skin lesions) were submitted for necropsy.

Table 1

Cases by farm

\begin{tabular}{lllcccc}
\hline Farm & Population & Course & Diseased & Died & Euthanised & Case no. \\
\hline A & 3 porkers $\left.^{\S}\right)$ & Subacute & 1 & & $1^{\&}$ & 1 \\
B & $2\left(\right.$ porkers $\left.^{\S}\right)$ & Chronic & 1 & & $1^{\$}$ & 2 \\
& & mild, recovered & 1 & & & \\
C & 27 (sows + offspring) & Acute & 3 & 1 sow & & 3 \\
& & & & 2 piglets & & 4 \\
\hline
\end{tabular}

${ }^{\&}$ No improvement after 4 days of antibiotic treatment. ${ }^{\$}$ Improvement after 4 days of antibiotic treatment although severe skin lesions persisted. ${ }^{*}$ Case number assigned at postmortem examination. ${ }^{\S}$ Porker $=$ fattening pig with a body weight over $100 \mathrm{~kg}$

\section{Gross pathological, histopathological and immunohistochemical examinations}

Postmortem examination was carried out according to standard procedures. A range of tissue samples were collected after the gross pathological examination, fixed in 10\% neutral buffered formalin, embedded in paraffin (Table 2), sectioned at $4 \mu \mathrm{m}$ thick, and stained using haematoxylin and eosin or BrownBrenn.

Immunohistochemistry (IHC) was used on tissue sections of each case to detect pasteurella antigens (Szeredi et al., 2010). Briefly, after antigen retrieval by microwave heat treatment at $750 \mathrm{~W}$ for $20 \mathrm{~min}$ in a $\mathrm{pH} 6.0$ citrate buffer, the sections were incubated overnight with rabbit polyclonal hyperimmune serum raised against Bibersteinia trehalosi serotype 3 (which also recognises Mannheimia haemolytica, $P$. aerogenes and $P$. multocida) at 1:2,000 dilution at room 
temperature. Antibody binding was detected by a horseradish peroxidase-labelled polymer kit (ENVISION+; Dako, Glostrup, Denmark). Negative controls were prepared from adjacent tissue sections by replacing the primary antibody with a phosphate-buffered solution. Sections of lung from pigs infected with $P$. multocida were used as a positive control.

Table 2

Identification of Pasteurella multocida from postmortem samples via bacterial culture, histopathological lesions and immunohistochemical detection of antigens

\begin{tabular}{lcccc}
\hline & \multicolumn{4}{c}{ Culture/lesions/antigen $^{*}$} \\
& 1 & 2 & 3 & 4 \\
\cline { 2 - 4 } Case number & $\mathrm{ND} / /-$ & $\mathrm{ND}$ & $-/+/+$ & $\mathrm{ND} /+/+$ \\
Brain & $-/+/-$ & $\mathrm{ND} /+/-$ & $+/+/+$ & $-/+/+$ \\
Lungs & $-\mathrm{ND} / \mathrm{ND}$ & $\mathrm{ND} /-/+$ & $\mathrm{ND} /+/+$ & $\mathrm{ND} /+/+$ \\
Liver & $-/+/+$ & $-/+/+$ & $+/+/+$ & $-/+/+$ \\
Spleen & $\mathrm{ND} / /+$ & $+/+/+$ & $\mathrm{ND} /+/+$ & $\mathrm{ND} /+/+$ \\
Kidney & $-\mathrm{ND} / \mathrm{ND}$ & $-/+/+$ & $\mathrm{ND}$ & $\mathrm{ND} /+/+$ \\
Lymph node & $\mathrm{ND}$ & $+/+/+$ & $\mathrm{ND}$ & $\mathrm{ND}$ \\
Tonsil & $+/+/+$ & $+/+/+$ & $+/ \mathrm{ND} / \mathrm{ND}$ & $+/ \mathrm{ND} / \mathrm{ND}$ \\
Skin & & & \\
\hline
\end{tabular}

${ }^{*} \mathrm{ND}$ - not done

\section{Bacteriological examinations}

Samples for bacterial culture were collected from the spleen and affected skin and subcutaneous tissues from all cases, as well as the lungs, mesenteric lymph nodes, brain, liver, kidney and tonsils in some cases (Table 2). Bacterial culture was performed using Columbia agar (LAB M Ltd., Bury, UK) supplemented with $10 \%$ blood under aerobic conditions at $37^{\circ} \mathrm{C}$ for $24-48 \mathrm{~h}$. Presumptive identification of isolates was based on colony morphology, Gram staining characteristics and biochemical properties (indole production, nitrate reduction, urease activity, and the ability to ferment glucose and saccharose).

Biovar determination was via carbohydrate fermentation patterns and ornithine decarboxylase activity. Production of ornithine decarboxylase was determined in the presence of 1\% L-ornithine. Lactose, maltose, arabinose, trehalose, xylose, dulcitol and sorbitol tests were performed using peptone water, sterile solutions of sugars or alcohols, and bromothymol blue in a final concentration of $1 \%$, with the test tubes incubated at $37^{\circ} \mathrm{C}$ for $24 \mathrm{~h}$.

\section{Identification of species, capsular type and somatic serotype}

Presumptive isolate identification was confirmed using a species-specific PCR assay (Townsend et al., 1998a). Combinations of oligonucleotide primers were used for amplification of kmtl (species identification), toxA (P. multocida toxin) and hyaC-hyaD (capsular serogroup A) sequences in the same reaction (Gautam 
et al., 2004; Register and DeJong, 2006). The capsular type was identified using a multiplex PCR method as described previously (Townsend et al., 2001).

The somatic serotype was determined using PCR-RFLP (PCR followed by a restriction fragment length polymorphism assay) based on ompH polymorphisms per the method of Sellyei et al. (2013). Amplification of the target sequence was performed using oligonucleotide primers described by Antony et al. (2007). PCR products were digested using the FastDigest ${ }^{\mathrm{TM}}$ DraI restriction endonuclease as per the manufacturer's directions (Thermo Scientific). Fragment lengths were determined using agarose gel electrophoresis imaged with Kodak Molecular Imaging Software (version 5.0).

\section{Bacterial strains}

Three suspected P. multocida isolates (designated as P55, P56 and P57) from cases of generalised porcine pasteurellosis were further characterised. A further 20 P. multocida strains isolated from pigs in Hungary representing capsule types A, D and F were also used for genetic typing (Table 3). Reference strains of all known capsular types [X73 (A), M1404 (B), P3881 (D), P1235 (E) and P4679 (F)] were kindly provided by Dr. R. B. Rimler (Ames, IA, USA).

Table 3

Bacterial strains used for genetic typing

\begin{tabular}{lccc}
\hline Strain & Host & Origin & Capsular type \\
\hline M1404 & bison & USA & B \\
P55 & pig & Kisbér & B \\
P56 & pig & Kisbér & B \\
P57 & pig & Kisbér & B \\
P220 & pig & Mezőhegyes & A \\
P307 & pig & Mezőhegyes & A \\
P628 & pig & Ács & A \\
P630 & pig & Ács & D \\
P662 & pig & Szőny & D \\
P668 & pig & Szőny & A \\
P704 & pig & Karancsság & D \\
P752/1 & pig & Rábakecöl & A \\
P752/2 & pig & Rábakecöl & A \\
P775 & pig & Bábolna & D \\
P846 & pig & Bábolna & F \\
P870 & pig & Borota & A \\
P880 & pig & Komárom & A \\
P882 & pig & Ács & A \\
P1012 & pig & Töltéstava & A \\
P1092 & pig & Rábakecöl & A \\
P1113 & pig & Nagykőrös & D \\
P1140 & pig & Bana & A \\
P1150 & wild boar & Unknown & D \\
P1194 & pig & Herceghalom & A \\
\hline
\end{tabular}




\section{DNA preparation}

A loopful of cultured bacterial growth was suspended in $50 \mu \mathrm{L}$ sterile double-distilled water and heated in a thermal cycler for $20 \mathrm{~min}$ at $99^{\circ} \mathrm{C}$. Cellular debris was pelleted by centrifugation and the supernatant used as the DNA template for PCR amplification.

\section{Virulence-associated genes}

To determine virulence-associated genes, multiple adhesins were tested: type I and type IV fimbrial subunits (fimA, ptfA), autotransporter adhesins (hsf-1, $h s f-2)$, tight adherence protein D (tadD), and filamentous haemagglutinin ( $p f h A)$. Genes were detected by PCR as previously described (Tang et al., 2009; Sellyei et al., 2010). All reactions were performed using a C1000 Thermal Cycler (BioRad Laboratories, Inc., Berkeley, CA, USA). Reference strain M1404 was used as a known control.

\section{M13 PCR}

M13 PCR was used to compare the isolates from this study with other $P$. multocida strains isolated from pigs in Hungary. This differentiates strains based on random amplification of polymorphic DNA. The reaction was performed using M13 core primer (5'-GAGGGTGGCGGTTCT-3') as previously described (Hunt Gerardo et al., 2001). Determination of accurate fragment lengths was made using agarose gel electrophoresis imaged with Kodak Molecular Imaging Software (version 5.0).

\section{Multilocus sequence typing (MLST)}

The genetic relationships of $P$. multocida P55, P56 and P57 were analysed by sequencing seven housekeeping genes. MLST was performed as described by Davies et al. (2004). Purification and sequencing of PCR products from both strands were performed by Macrogen Europe (Amsterdam, The Netherlands). Nucleotide sequences were aligned and compared using BioEdit software (version 7.2.3) (Hall, 1999). Sequence data were analysed using a web-based MLST method (http://cge.cbs.dtu.dk/services/MLST/). Sequence types and allelic profiles were submitted to the $P$. multocida multihost MLST database (http://pubmlst. org/pmultocida_multihost/). A neighbour-joining tree was drawn from the concatenated sequences (3990 bp) using MEGA 5.2 (Tamura et al., 2011). 


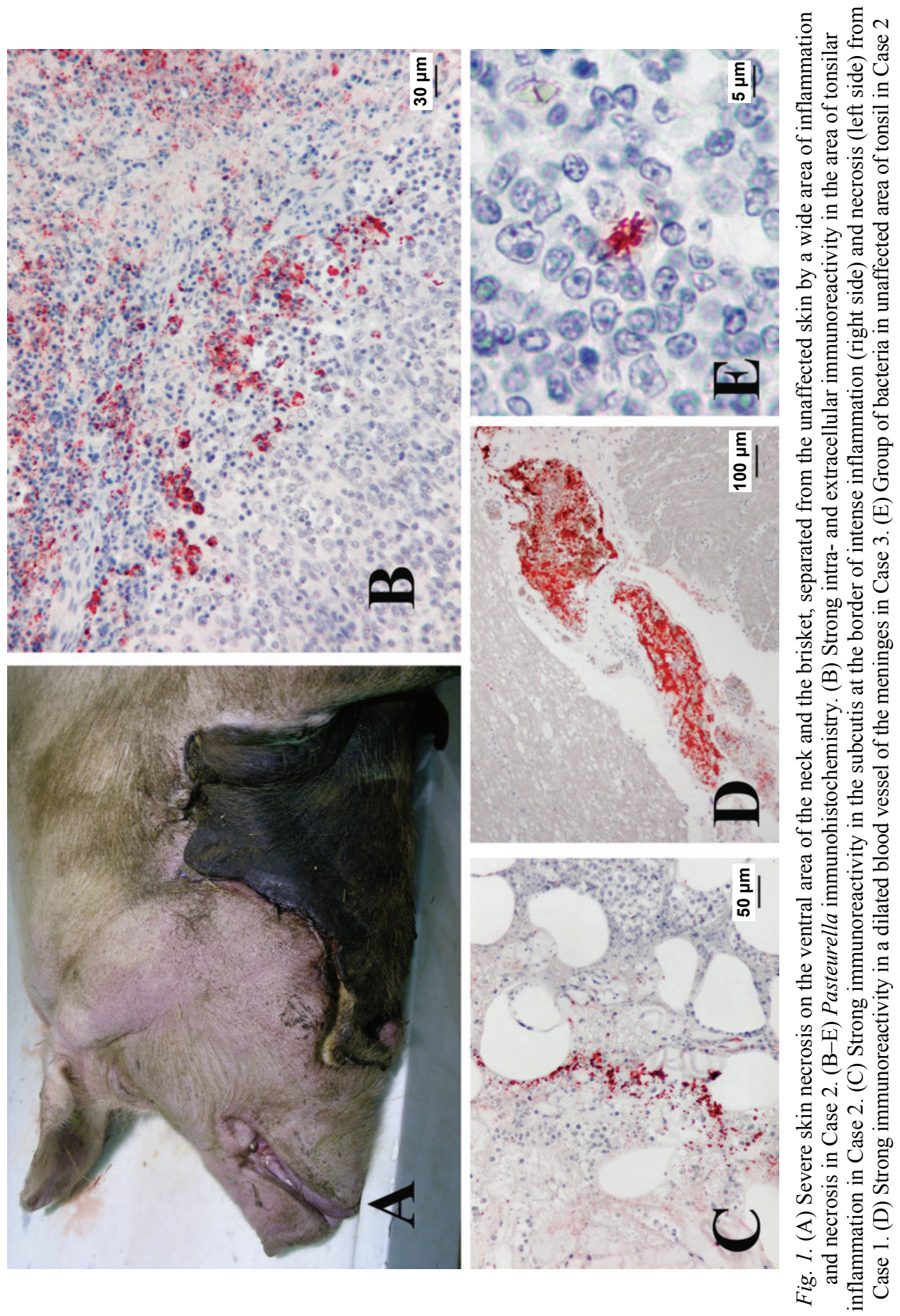




\section{Results}

The most characteristic macroscopic lesions were in the skin of the ventral neck and brisket. The affected areas were irregular, firm, dark red to purple and slightly elevated, with a sharp line of demarcation between affected and adjacent normal tissues in Cases 1, 3 and 4. When sectioned, the dermis and subcutis were severely oedematous and disrupted by multiple haemorrhages. In Case 2, the skin lesions were similar but the epidermis was black, dry and hard and was separated from the unaffected skin by a wide area of purulent inflammation and tissue necrosis (Fig. 1A). The underlying subcutis was severely oedematous and yellow. The subjacent adipose tissues and skeletal muscles had haemorrhagic and necrotic foci 1 to $2 \mathrm{~cm}$ in diameter. The liver, kidney, spleen and mesenteric lymph nodes were congested and slightly enlarged in Cases 3 and 4. The submandibular lymph nodes in Case 2 and the mesenteric lymph nodes in Case 1 were also enlarged. Multiple grey to white foci $5 \mathrm{~mm}$ in diameter were observed in the cortices of the kidneys in Case 2. No significant lesions were found in the remaining organs.

Histopathology revealed severe oedema, acute haemorrhages, several acute microthrombi, focal necrosis and acute purulent inflammation in the dermis and subcutis in Case 1 (Fig. 1C). Additionally, the epidermis and large areas of the dermis and subcutis were necrotic and separated from adjacent normal tissues by a zone of neutrophils, macrophages, multinucleated giant cells, and fibrocytes in Case 2. Acute haemorrhages were found in the spleen (all cases), lungs (Cases 1, 3 and 4), kidneys (Cases 3 and 4), and liver (Case 4). Other common lesions included acute meningitis (Cases 3 and 4) and encephalitis (Case 4), acute multifocal splenic necrosis (Cases 3 and 4), acute hepatitis (Cases 3 and 4) and lymphadenitis (Case 2), and mild lymphohistiocytic interstitial pneumonia (Cases 2 and 4) accompanied in one case by acute catarrhal to purulent bronchopneumonia (Case 4). Finally, one case had multifocal, necrotic, purulent tonsillitis, vasculitis and perivasculitis, focal fibrinoid necrosis in the liver, and acute to chronic, multifocal interstitial nephritis (Case 2). Microthrombi and bacterial emboli containing Gram-negative rods were evident in the lungs and in the brain, especially in the meninges (Cases 3 and 4), the skin (Cases 1 and 2), the spleen (Case 3), the kidneys (Cases 3 and 4) and in the mesenteric lymph nodes (Case 4).

Pasteurella antigens were detected in cocci or short rods both extracellularly and within macrophages in several tissue samples (Table 2). Intravascular bacterial emboli and microthrombi in the skin (Cases 1 and 2), lungs (Cases 3 and 4), brain (Fig. 1D), spleen and kidneys (Case 3) had abundant pasteurella immunoreactivity. Additionally, large numbers of bacteria were found in the areas of inflammation in the skin (Cases 1 and 2; Fig. 1C), in the inflammatory cells in the lumina and walls of alveoli in the lungs (Case 4), and within the foci of necrosis and suppurative inflammation in the tonsils (Case 2; Fig. 1B). Fur- 
thermore, one to five bacteria were detected in all cases in different tissue samples (Fig. 1E). Extracellular bacteria were detected in both affected and unaffected tissues of the tonsils, splenic sinusoids, lymph nodes, liver, in the tubular lumina of the kidneys and in the cerebral neuropil.

Pasteurella multocida was isolated from affected areas of the skin in all cases, from the lungs and spleen in Case 3, and from the kidney and tonsil in Case 2 (Table 2). Tests for classical and African swine fever, PRRSV and PCV2 were negative in all cases. Three isolates from the present outbreak ( $P$. multocida P55, P56 and P57) were identified as P. multocida ssp. multocida. They fermented xylose and sorbitol and showed ornithine decarboxylase activity but did not produce acid from arabinose, maltose, lactose, trehalose and dulcitol. On the basis of fermentation abilities, the strains were assigned to biovar 3 , and serotyping determined these isolates as $\mathrm{B}: 2$. The tox $A$ gene was not detected in any isolate.

All capsular type B strains (including the M1404 reference strain) showed the same genetic profile. These strains harboured genes encoding $p t f A$ (allelic variant B), fim $A$, $h s f-2$ and $p f h A$, while genes encoding $h s f-1$ and tadD were not detected. The isolates showed some differences compared with porcine strains from Hungary with different capsular types (Table 4). The $h s f-1$ gene was detected in most of the strains $(14 / 20)$ but not in the B:2 strains. However, pfhA was less prevalent $(5 / 20)$ in the other strains than in the type B isolates (4/4). The tight adherence protein coding tadD was not found in the B:2 strains. The fimA and $h s f-2$ genes were highly prevalent in all strains.

Using M13 PCR, three different genomic fingerprints were detected (Table 4, Fig. 2). The 24 strains showed type-specific band patterns with products varying from $300 \mathrm{bp}$ to $1.6 \mathrm{~kb}$. Five bands were present in all strains, and two bands (1255 and $1296 \mathrm{bp}$ ) were identified only in type B isolates. All B:2 strains showed the same fingerprint pattern (type I). Based on the presence or absence of three bands (1394, 979 and $770 \mathrm{bp})$, the rest of the strains were classified into group II or group III (18 and 2 strains, respectively).

MLST analysis of concatenated sequences from the B:2 strains (P55, P56 and P57) demonstrated a new sequence type (ST61), with allelic profile $a d k 26$, aroA 29, deoD 23, g6pd 23, gdhA 6, mdh 22 and pgi 25. An identical allele was found in aroA, with a nucleotide substitution at position $355(\mathrm{G} 355 \mathrm{~A})$ and a predicted amino acid change in the protein-coding region. ST61 is a double locus variant of ST44 and ST47 ( $a r o A$ and $g d h$ ) and has three different loci compared with ST45 (aroA, deoD and pgi) and ST46 (aroA, deoD and $g d h$ ). Comparison to isolates in the multi-host MLST database revealed a clearly separated cluster of HS-causing STs with high bootstrap support values. A neighbour-joining dendrogram was constructed to represent the genetic distance of these closely related STs (Fig. 3). 
Table 4

M13 PCR patterns of 24 P. multocida strains and distribution of capsular type and virulenceassociated genes

\begin{tabular}{|c|c|c|c|c|c|c|c|c|c|}
\hline Strain ID & $\begin{array}{l}\text { Capsular } \\
\text { type }\end{array}$ & $\begin{array}{l}\text { M13 } \\
\text { type }^{\mathrm{a}}\end{array}$ & tox $A$ & $p t f A$ & $\operatorname{fim} A$ & $h s f-1$ & $h s f-2$ & $\operatorname{tad} D$ & $p f h A$ \\
\hline P220 & A & II (7) & + & B & + & + & - & - & - \\
\hline P307 & A & II (8) & + & B & + & + & + & - & - \\
\hline P628 & A & II (11) & + & B & + & + & + & - & - \\
\hline P668 & A & III (12) & - & B & + & - & + & + & + \\
\hline P752/1 & A & II & + & B & + & + & + & - & - \\
\hline $\mathrm{P} 752 / 2$ & A & II & - & B & + & - & + & + & - \\
\hline P870 & A & II & + & B & + & + & + & - & - \\
\hline P880 & A & II & - & B & + & - & + & + & + \\
\hline P882 & A & II (6) & - & B & + & - & + & + & - \\
\hline P1012 & A & II & - & B & + & - & + & + & - \\
\hline P1092 & A & II (9) & + & B & + & + & + & - & - \\
\hline P1140 & A & II & - & B & + & - & + & + & - \\
\hline P1194 & A & II & + & B & + & + & + & - & - \\
\hline M1404 & B & I (5) & - & B & + & - & + & - & + \\
\hline P55 & B & I (2) & - & B & + & - & + & - & + \\
\hline P56 & B & I (3) & - & B & + & - & + & - & + \\
\hline P57 & B & I (4) & - & B & + & - & + & - & + \\
\hline P630 & D & II & - & B & + & + & + & - & - \\
\hline P662 & $\mathrm{D}$ & II & - & B & + & + & + & - & - \\
\hline P704 & $\mathrm{D}$ & II (10) & - & B & + & + & + & + & + \\
\hline P775 & D & III & - & B & + & + & + & - & - \\
\hline P1113 & $\mathrm{D}$ & II & + & B & + & + & + & + & + \\
\hline P1150 & $\mathrm{D}$ & II & + & B & + & + & + & - & - \\
\hline P846 & $\mathrm{F}$ & II & - & B & + & + & + & - & + \\
\hline
\end{tabular}

${ }^{a}$ Numbers in parentheses correspond to the lane assignments in Fig. 2

\section{Discussion}

The P. multocida isolated from these backyard pigs had not been previously detected in Hungary. The source of infection and the immediate reason of disease onset could not be determined. It is possible that a latent infection was exacerbated by the hot weather immediately prior to the development of clinical signs. However, no epidemiological relationship could be established between the affected pigs and any other animal species or fomites suitable for carrying the pathogen.

Septicaemic pasteurellosis caused by P. multocida type B is usually characterised by high morbidity and mortality with peracute or acute disease onset (Gamage et al., 1995; Townsend et al., 1998b; Cardoso-Toset et al., 2013). In these cases, the number of affected animals was relatively low. In addition, there 
were remarkable differences in disease progression, varying from acute to chronic. This could be because the farms kept a small number of mostly older animals, which could limit the chances for the pathogen to replicate in susceptible hosts, decreasing the likelihood of transmission.

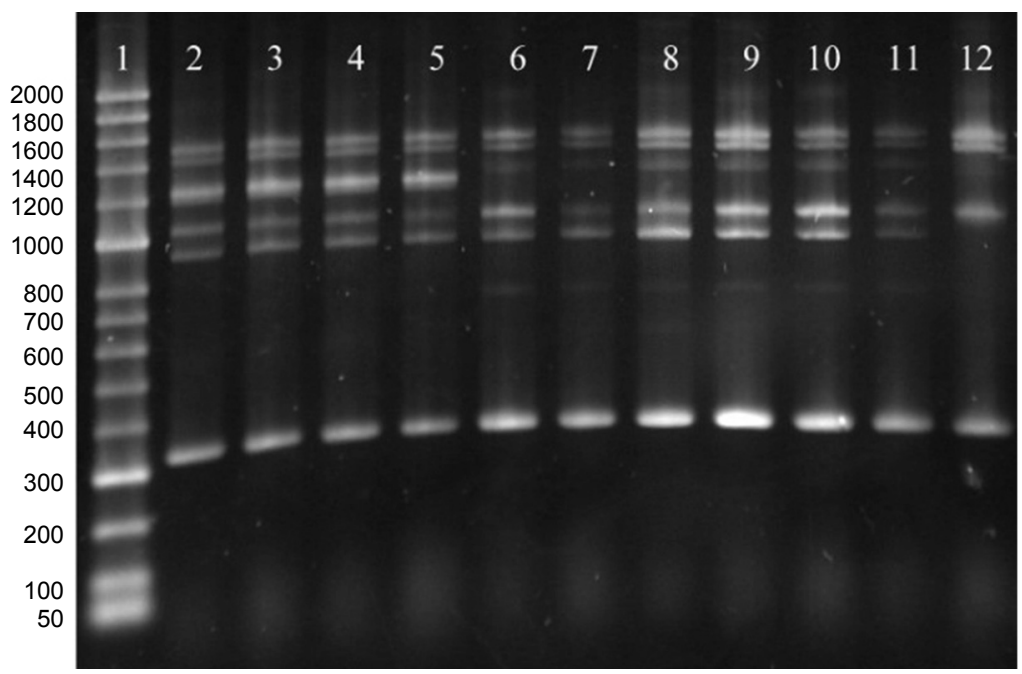

Fig. 2. Pasteurella multocida fingerprint profiles generated by M13 PCR. Lane 1, DNA ladder; lanes 2-4, isolates from generalised pasteurellosis; lane 5, P. multocida M1404; lanes 6-11, representative group II PCR fingerprint profiles; lane 12, representative group III PCR fingerprint profile. Lane numbers correspond to fingerprint types and the representative strains in parentheses in Table 4

An early report of acute porcine pasteurellosis due to P. multocida type B was given by Murty and Kaushik (1965). Some characteristics of these cases were similar to those of the cases reported here; relatively small numbers of pigs were affected, skin lesions were the dominant clinical signs, and there was a sudden onset and a brief clinical course. The differences in the clinical picture of type $\mathrm{B}$ pasteurellosis may be due to as-yet undiscovered genotypic or host factors. As the macroscopic haemorrhages were restricted to the skin and P. multocida was only isolated from some of the samples rather than all, the term generalised pasteurellosis seems more appropriate for these cases than haemorrhagic septicaemia.

Dermatitis was the most characteristic lesion in all cases examined, as no pathognomonic lesions were detected in other organs. Histopathology, however, revealed inflammation and haemorrhages in several tissues, including the spleen, lung, kidney and liver, and IHC confirmed the presence of $P$. multocida in these samples. Typically, latently infected animals are responsible for maintaining $P$. multocida infections in a population. The tonsils frequently serve as a reservoir for the bacteria, which may spread by droplet transmission to other animals. In- 
fection of the tonsils was demonstrated in Case 4 via both bacterial culture and IHC. This animal survived the infection and became clinically normal aside from skin lesions after a few days of illness. Although the animal was in good body condition, it was euthanised as the severe skin lesions would make slaughter impossible.

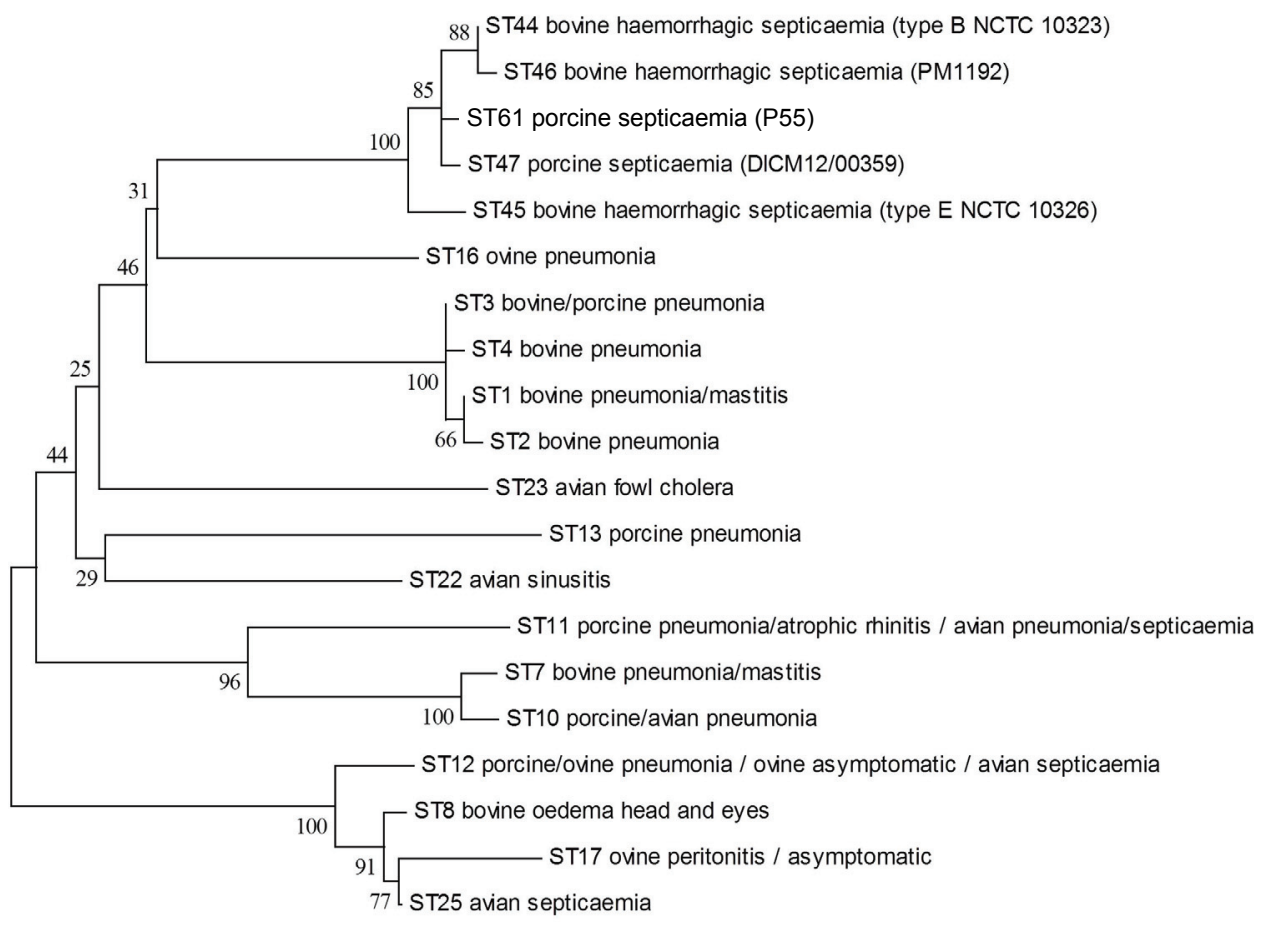

$\longmapsto .001$

Fig. 3. Evolutionary relationships of $P$. multocida strains from various hosts and disease phenotypes. Evolutionary history was inferred using the neighbour-joining method. The percentage of replicate trees where the associated taxa clustered together in a bootstrap test with 1000 replicates is shown next to the branches. Evolutionary distances were computed using the maximum composite likelihood method and are in the units of the number of base substitutions per site

Our isolates were identified as P. multocida ssp. multocida biovar 3, which is the most common biovar in pigs (Blackall et al., 1997; García et al., 2011). Recently, Cardoso-Toset et al. (2013) isolated type B P. multocida from an outbreak of septicaemic pasteurellosis in free-range pigs with an atypical biovar for pigs (it was reported as biovar 13, although its lactose fermentation ability suggests that it belongs to biovar 14 , which is a lactose-positive and ornithine decarboxylase-negative variant of $P$. multocida ssp. multocida) (Blackall et al., 1997). Currently, the significance of biovar diversity is unknown. 
Genotyping methods based on the analysis of hypervariable repetitive DNA regions are effective techniques for epidemiological studies. Using the core sequence of phage M13 that detects mini-satellite DNA has proven to be a rapid, simple-to-perform and sensitive method to identify strain to strain variations (Hunt Gerardo et al., 2001). Our examination of genetic relatedness among porcine isolates confirmed the clonal identity of the septicaemic strains. The findings of this study are consistent with those of Townsend et al. (1997, 1998b), who found that septicaemia-associated isolates demonstrated only slight diversity and were genotypically identical to other HS-causing isolates. At the same time, their isolate represented a sequence type (ST47) different from ours (ST61), indicating that the two infections originated from unrelated sources.

Adhesion-related genes are key components in the colonisation of host tissues. However, our knowledge on virulence factors involved in host interactions in P. multocida type B isolates is limited. The current study found that type B strains harboured the same set of virulence-associated genes, while strains of other serotypes showed variations in their genetic profiles. This agrees with the results of Ewers et al. (2006), who reported that, in contrast to other serotypes, all type B strains possessed the filamentous haemagglutinin gene $p f h A$. Furthermore, the $P$. multocida strains we examined had high prevalences of the fimA, $p t f A$ and $h s f-2$ genes, which is also similar to the results of previous studies (Ewers et al., 2006; Tang et al., 2009). Interestingly, the autotransporter adhesin gene $h s f-1$ is associated with type D strains with a lower prevalence in type A isolates. However, no correlation was found between the tadD gene and type A isolates. Therefore, type B strains are highly homogeneous with respect to adhesionrelated genes, which may indicate their pathogenic potential and strong host specificity. Moreover, this could indicate a more recent divergence from the ancestral strain.

No differences were found among the clinical isolates we examined from the outbreak with either traditional or molecular methods, indicating that they represent a single strain of $P$. multocida. This strongly suggests that the affected pigs became infected from a single as yet undetected source. MLST analysis showed that these isolates were closely related to other HS-causing strains of porcine and bovine origin. Our results confirm that HS-causing strains of $P$. multocida form a distinct phylogenic group within the species of $P$. multocida regardless of the host species.

In conclusion, this is the first description of type B P. multocida in Hungary isolated from a sporadic outbreak of generalised pasteurellosis in backyard pigs. The source of the infection remained undetermined. MLST analysis revealed that our isolates represented a new sequence type (ST61) showing close relationship with other HS-causing strains of $P$. multocida independently of the host of origin. 


\section{Acknowledgements}

The authors thank Dr. Enikö Wehmann for her useful comments. This study was supported by the Hungarian Scientific Research Fund (OTKA, project no. K81690).

\section{References}

Antony, P. X., Nair, G. K., Jayaprakasan, V., Mini, M. and Aravindakshan, T. V. (2007): Nucleic acid based differentiation of Pasteurella multocida serotypes. Int. J. Vet. Med. 2, 85-89.

Biswas, A., Shivachandra, S. B., Saxena, M. K., Kumar, A. A., Singh, V. P. and Srivastava, S. K. (2004): Molecular variability among strains of Pasteurella multocida isolated from an outbreak of haemorrhagic septicaemia in India. Vet. Res. Comm. 28, 287-298.

Blackall, P. J., Fegan, N., Chew, G. T. and Hampson, D. J. (1998): Population structure and diversity of avian isolates of Pasteurella multocida from Australia. Microbiol. 144, $279-289$.

Blackall, P. J., Pahoff, J. L. and Bowles, R. (1997): Phenotypic characterisation of Pasteurella multocida isolates from Australian pigs. Vet. Microbiol. 57, 355-360.

Boyce, J. D., Harper, M., Wilkie, I. W. and Adler, B. (2010): Pasteurella. In: Gyles, C. L., Prescott, J. F., Songer, J. G. and Thoen, C. O. (eds) Pathogenesis of Bacterial Infections in Animals. 4th edition. Iowa State University Press, Ames, IA, USA. pp. 325-346.

Cardoso-Toset, F., Gómez-Laguna, J., Callejo, M., Vela, A. I., Carrasco, L., FernándezGarayzábal, J. F., Maldonado, A. and Luque, I. (2013): Septicaemic pasteurellosis in freerange pigs associated with an unusual biovar 13 of Pasteurella multocida. Vet. Microbiol. 167, 690-694.

Carter, G. R. (1955): Studies on Pasteurella multocida. I. A hemagglutination test for the identification of serological types. Am. J. Vet. Res. 16, 481-484.

Carter, G. R. and De Alwis, M. C. L. (1989): Haemorrhagic septicaemia. In: Adlam, C. and Rutter, J. M. (eds) Pasteurella and Pasteurellosis. Academic Press Limited, London, England. pp. 131-160.

Christensen, H., Kuhnert, P., Olsen, J. E. and Bisgaard, M. (2004): Comparative phylogenies of the housekeeping genes $a t p \mathrm{D}$, inf $\mathrm{B}$ and $r p o \mathrm{~B}$ and the $16 \mathrm{~S}$ rRNA gene within the Pasteurellaceae. Int. J. Syst. Evol. Microbiol. 54, 1601-1609.

Davies, R. L. (2004): Genetic diversity among Pasteurella multocida strains of avian, bovine, ovine and porcine origin from England and Wales by comparative sequence analysis of the 16S rRNA gene. Microbiol. 150, 4199-4210.

Davies, R. L., MacCorquodale, R. and Reilly, S. (2004): Characterisation of bovine strains of Pasteurella multocida and comparison with isolates of avian, ovine and porcine origin. Vet. Microbiol. 99, 145-158.

De Alwis, M. C. L. (1992): Haemorrhagic septicaemia - A general review. Br. Vet. J. 148, 99-112.

Ewers, C., Lübke-Becker, A., Bethe, A., Kießling, S., Filter, M. and Wieler, L. H. (2006): Virulence genotype of Pasteurella multocida strains isolated from different hosts with various disease status. Vet. Microbiol. 114, 304-317.

Fegan, N., Blackall, P. J. and Pahoff, J. L. (1995): Phenotypic characterisation of Pasteurella multocida isolates from Australian poultry. Vet. Microbiol. 47, 281-286.

Gamage, L. N. A., Wijewardana, T. G., Bastiansz, H. L. G. and Vipulasiri, A. A. (1995): An outbreak of acute pasteurellosis in swine caused by serotype B:2 in Sri Lanka. Sri Lanka Vet. J. 42, 15-19.

García, N., Fernández-Garayzábal, J. F., Goyache, J., Domínguez, L. and Vela, A. I. (2011): Associations between biovar and virulence factor genes in Pasteurella multocida isolates from pigs in Spain. Vet. Rec. 169, 362. 
Gautam, R., Kumar, A. A., Singh, V. P., Vijendra, P., Dutta, T. K. and Shivachandra, S. B. (2004): Specific identification of Pasteurella multocida serogroup-A isolates by PCR assay. Res. Vet. Sci. 76, 179-185.

Hall, T. A. (1999): BioEdit: a userfriendly biological sequence alignment editor and analysis program for Windows 95/98/NT. Nucleic Acids Symp. Ser. 41, 95-98.

Heddleston, K. L., Gallagher, J. E. and Rebers, P. A. (1972): Fowl cholera: Gel diffusion precipitin test for serotyping Pasteurella multocida from avian species. Avian Dis. 16, 925-936.

Holst, E., Rollof, J., Larsson, L. and Nielsen, J. P. (1992): Characterization and distribution of Pasteurella species recovered from infected humans. J. Clin. Microbiol. 30, 2984-2987.

Hotchkiss, E. J., Hodgson, J. C., Schmitt-van de Leemput, E., Dagleish, M. P. and Zadoks, R. N. (2011): Molecular epidemiology of Pasteurella multocida in dairy and beef calves. Vet. Microbiol. 151, 329-335.

Hunt Gerardo, S., Citron, D. M., Claros, M. C., Fernandez, H. T. and Goldstein, E. J. C. (2001): Pasteurella multocida subsp. multocida and P. multocida subsp. septica differentiation by PCR fingerprinting and $\alpha$-glucosidase activity. J. Clin. Microbiol. 39, 2558-2564.

Mackie, J. T. (1996): Haemorrhagic septicaemia in pigs. Aust. Vet. J. 74, 399-400.

Magyar, T. and Lax, A. J. (2002): Atrophic rhinitis. In: Brogden, K. A. and Guthmiller, J. M. (eds) Polymicrobial Diseases. ASM Press, Washington DC, USA. pp. 169-197.

Murty, D. K. and Kaushik, R. K. (1965): Studies on an outbreak of acute swine pasteurellosis due to Pasteurella multocida type B (Carter, 1955). Vet. Rec. 77, 411-416.

Mutters, R., Ihm, P., Pohl, S., Frederiksen, W. and Mannheim, W. (1985): Reclassification of the genus Pasteurella Trevisan 1887 on the basis of deoxyribonucleic acid homology, with proposals for the new species Pasteurella dagmatis, Pasteurella canis, Pasteurella stomatis, Pasteurella anatis, and Pasteurella langaa. Int. J. Syst. Bacteriol. 35, 309-322.

Petersen, A., Bisgaard, M., Townsend, K. and Christensen, H. (2014): MLST typing of Pasteurella multocida associated with haemorrhagic septicaemia and development of a real-time PCR specific for haemorrhagic septicaemia associated isolates. Vet. Microbiol. 170, 335-341.

Register, K. B. and DeJong, K. D. (2006): Analytical verification of a multiplex PCR for identification of Bordetella bronchiseptica and Pasteurella multocida from swine. Vet. Microbiol. 117, 201-210.

Rhoades, K. R. and Rimler, R. B. (1989): Fowl cholera. In: Adlam, C. and Rutter, J. M. (eds) Pasteurella and Pasteurellosis. Academic Press Limited, London, England. pp. 95-113.

Rimler, R. B. and Rhoades, I. R. (1987): Serogroup F, a new capsule serogroup of Pasteurella multocida. J. Clin. Microbiol. 25, 615-618.

Sellyei, B., Bányai, K. and Magyar, T. (2010): Characterization of the ptfA gene of avian Pasteurella multocida strains by allele-specific polymerase chain reaction. J. Vet. Diagn. Invest. 22, 607-610.

Sellyei, B., Ivanics, É. and Magyar, T. (2013): Characterisation of avian Pasteurella multocida strains with PCR-RFLP analysis of the ompH gene. Acta Vet. Hung. 61, 1-8.

Sellyei, B., Wehmann, E., Makrai, L. and Magyar, T. (2011): Evaluation of the Biolog system for the identification of certain closely related Pasteurella species. Diagn. Microbiol. Infect. Dis. 71, 6-11.

Szeredi, L., Jánosi, Sz. and Pálfi, V. (2010): Microbiological and pathological examinations of fatal calf pneumonia cases induced by bacterial and viral respiratory pathogens. Acta Vet. Hung. $\mathbf{5 8 , 3 4 1 - 3 5 6 . ~}$

Tamura, K., Peterson, D., Peterson, N., Stecher, G., Nei, M. and Kumar, S. (2011): MEGA5: Molecular Evolutionary Genetics Analysis using maximum likelihood, evolutionary distance, and maximum parsimony methods. Mol. Biol. Evol. 28, 2731-2739.

Tang, X., Zhao, Z., Hu, J., Wu, B., Cai, X., He, Q. and Chen, H. (2009): Isolation, antimicrobial resistance, and virulence genes of Pasteurella multocida strains from swine in China. J. Clin. Microbiol. 47, 951-958. 
Townsend, K. M., Boyce, J. D., Chung, J. Y., Frost, A. J. and Adler, B. (2001): Genetic organization of Pasteurella multocida cap loci and development of a multiplex capsular PCR typing system. J. Clin. Microbiol. 39, 924-929.

Townsend, K. M., Dawkins, H. J. and Papadimitriou, J. (1997): REP-PCR analysis of Pasteurella multocida isolates that cause haemorrhagic septicaemia. Res. Vet. Sci. 63, 151-155.

Townsend, K. M., Frost, A. J., Lee, C. W., Papadimitriou, J. M. and Dawkins, H. J. S. (1998a): Development of PCR assays for species- and type-specific identification of Pasteurella multocida isolates. J. Clin. Microbiol. 36, 1096-1100.

Townsend, K. M., O’Boyle, D., Thi Phan, T., Xuan Hanh, T., Wijewardana, T. G., Wilkie, I., Tien Trung, N. and Frost, A. J. (1998b): Acute septicaemic pasteurellosis in Vietnamese pigs. Vet. Microbiol. 63, 205-215. 